\title{
A SELETIVIDADE DO IMPOSTO SOBRE PRODUTOS INDUSTRIALIZADOS COMO INSTRUMENTO DE INTERVENÇÃO DO ESTADO NA ECONOMIA: Análise do Mercado de Consumo de Veículos e Tabaco, no Período de 2010 a 2016
}

\author{
http://dx.doi.org/10.21527/2176-6622.2019.51.123-139
}

Recebido em: 3/1/2019

Modificações requeridas em: 18/5/2019

Aceito em: 21/5/2019

\section{Maurin Almeida Falcão}

Pós-doutorado (estágio realizado no \&quot; Groupement Européen de Recherches en Finances Publiques Gerfip\&quot - Universidade de Paris I-Panthéon-Sorbonne, jun./2012-jun./2013). Doutorado em Direito Público pela Universidade de Paris 11-Sud (2000), com a menção máxima \&quot; Très honorable, avec félicitations du jury\&quot. Obtenção da láurea European Label. Diploma de Estudos Superiores Especializados-Dess em Administração Tributária pela Universidade de Paris IX-Dauphine (1995). Aperfeiçoamento em Gestão das Finanças Públicas no Institut International dAdministration Publique/ENA (1987). Graduado em Ciências Contábeis pelo Centro de Ensino Unificado de Brasília (1981). Professor-adjunto da Universidade Católica de Brasília. Docente no Mestrado em Direito e nos cursos de Direito e de Relações Internacionais (Cátedra Jean Monnet) da Universidade Católica de Brasília. Atua na linha de pesquisa sobre Direito, Estado, Tributação e Desenvolvimento. Coordenador do Grupo de Estudo sobre os Sistemas Tributários Contemporâneos - Getric do Mestrado em Direito da Universidade Católica de Brasília. Membro fundador do Instituto Internacional de Ciências Fiscais e pesquisador do Grupo Europeu de Pesquisas em Finanças Públicas - Gerfip da Universidade de Paris I-Panthéon-Sorbonne.mfalcao@pos.ucb.br

\section{Luiz Fernando Oliveira}

Doutorado em Teoria e História do Direito pela Universidade Federal de Goiás (UFG). Mestrado em Direito pela Universidade Católica de Brasília (UCB). Especialização em Docência Universitária com ênfase em ensino jurídico pela Faculdade Católica de Anápolis. Bacharelado em Direito pelo Centro Universitário de Anápolis (UniEvangélica). Bacharelado e Licenciatura em História pela Universidade Federal de Goiás (UFG). luizfernandokerix@hotmail.com

\section{Acsa Reginaldo Silva}

Membro do Grupo de Estudos sobre os Sistemas Tributários Contemporâneos - Getric. Graduação em Direito pelo Centro Universitário de Anápolis (UniEvangélica) e em Ciências Econômicas pela Universidade Estadual de Goiás. Especializando em Direito Tributário pelo Centro Universitário de Anápolis (UniEvangélica). acsa.silva@tcm.go.gov.br

\section{RESUMO}

Constitui objeto deste estudo a seletividade do Imposto sobre Produtos Industrializados, de competência federal, e cuja alteração da alíquota prescinde da participação do Congresso Nacional, sendo atribuição do chefe do Poder Executivo, o qual fixa o percentual de incidência nos limites da Lei. Esta peculiaridade na fixação da alíquota representa uma exceção ao princípio da legalidade que, associada à supressão ao princípio da anterioridade de exercício, compõe o caráter extrafiscal do IPI. Neste contexto, o imposto pode ser utilizado como mecanismo de intervenção do Estado na economia, na medida em que a elevação ou diminuição da alíquota pode inibir ou estimular determinados comportamentos do consumidor. Por conseguinte, torna-se importante ressaltar o princípio da seletividade, o qual considera a essencialidade dos produtos para a fixação de alíquotas. Em decorrência, restringe-se a presente análise aos mercados consumidores de veículos e de tabaco, no período de 2010 a 2016, quando serão apreciados os efeitos das medidas extrafiscais do governo federal nestes setores produtivos. Ante a relevância da política econômica adotada no país, é imprescindível a avaliação dos efeitos da intervenção direta do Estado na economia, sobretudo para os consumidores e respectivos segmentos produtivos. A condução do presente trabalho se deu a partir de pesquisa exploratória com a utilização do método hipotético-dedutivo.

Palavras-chave: IPI. Intervenção estatal. Extrafiscalidade. Essencialidade. Seletividade. 


\section{Debate}

THE SELECTIVITY OF TAX ON INDUSTRIALIZED PRODUCTS AS AN INSTRUMENT OF STATE INTERVENTION IN THE ECONOMY: ANALYSIS OF THE MARKET FOR CONSUMPTION OF VEHICLES AND TOBACCO, FOR THE PERIOD 2010 TO 2016

\section{ABSTRACT}

The object of this study is the selectivity of the Tax on Industrialized Products, which is a federal jurisdiction and whose alteration of the tax rate does not involve the participation of the National Congress, being attributed by the head of the Executive Branch, which sets the percentage of incidence within the limits of the Law. in the determination of the rate represents an exception to the principle of legality that, associated to the elimination of the principle of prior exercise, make up the extra-fiscal nature of the IPI. In this context, the tax can be used as a mechanism for intervention by the State in the economy, since raising or lowering the tax rate may inhibit or stimulate certain consumer behavior. Therefore, it is important to emphasize the principle of selectivity, which considers the essentiality of the products for rates definition. As a result, the present analysis is restricted to the consumer vehicle and tobacco markets, from 2010 to 2016, where the effects of tax economics measures of the Federal Government in these productive sectors will be assessed. Given the importance of the economic policy adopted in the country, it is essential to evaluate the effects of the direct intervention of the State in the economy, especially for consumers and their productive segments. The conduction of the present work was based on an exploratory research using the hypothetical-deductive method.

Keywords: Tax on industrialized products. State intervention. Economics purpose of tax. Essentiality, Selectivity.

\section{SUMÁRIO}

1 Introdução. 20 tributo como mecanismo de intervenção do Estado na economia. 2.10 conceito de Estado intervencionista. 2.2 A função alocativa. 2.3 A função redistributiva. 3 Os objetivos da extrafiscalidade e da seletividade tributária. 4 A finalidade extrafiscal e seletiva do imposto sobre produtos industrializados. $4.1 \mathrm{O} \mathrm{IPI} \mathrm{como} \mathrm{instrumento} \mathrm{de} \mathrm{intervenção} \mathrm{do} \mathrm{Estado} \mathrm{na} \mathrm{economia.} 4.2$ Análise jurídica do IPI sob os aspectos da extrafiscalidade e da seletividade. 4.3 Uma análise empírica sobre o consumo do álcool, do tabaco e de veículos a partir da perspectiva seletiva e extrafiscal do IPI. 4.3.1 O segmento de veículos. 4.3.2 O segmento do tabaco. 5 Considerações finais. 6 Referências.

\section{INTRODUÇÃO}

Considerando-se a relevância da tributação como meio de financiamento do Estado, o presente trabaIho se propõe a examinar o Imposto sobre Produtos Industrializados (IPI) a partir dos seus aspectos jurídico e econômico. Com efeito, além de se constituir em importante fonte de receita do Estado, o imposto possui caráter extrafiscal, pois permite a sua utilização como importante instrumento de intervenção na economia.

A análise jurídica abrangerá todas as características do IPI, sobretudo no que se refere à sua extrafiscalidade e à sua seletividade. Estas atribuições extrapolam a função fiscal dos tributos e viabilizam a ação estatal de intervenção no domínio econômico, ao inibir ou fomentar determinados comportamentos na medida em que estimulam ou desestimulam determinados consumos. Deve ser observado, ainda, que o caráter extrafiscal do tributo permite a supressão dos princípios da legalidade e da anterioridade, à proporção que admite a alteração da alíquota por meio de decreto assinado pelo chefe do Poder Executivo. A seletividade, por sua vez, fundamenta-se no artigo 153, § 3으, inciso I da Constituição Federal, o qual estabelece como parâmetro para a aplicabilidade da alíquota do IPI a essencialidade do produto. Nesse sentido, o trabalho procedeu ao levantamento dos decretos emitidos pelo presidente da República, que alteraram as alíquotas do IPI para veículos e tabaco no período de 2010 a 2016. Tal procedimento justifica-se pela necessidade de se avaliar os efeitos produzidos por tais medidas extrafiscais nestes setores produtivos.

Considerando-se, portanto, que os mecanismos atrelados ao IPI produzem resultados nas esferas econômica e social, far-se-á uma abordagem econômica, com fundamento na Teoria da intervenção do Estado, mediante o acompanhamento do mercado consumidor de veículos, álcool e tabaco no período de 2010 a 2015 em face das alterações do IPI. Em decorrência, este trabalho foi estruturado para apresentar, em uma primeira parte, o tributo como mecanismo de intervenção do Estado na economia por meio das funções clássicas do tributo, quais sejam, a alocação, a redistribuição e a estabilização, com o intuito de justificar essa intervenção; a segunda foi dirigida aos objetivos da extrafiscalidade e da seletividade tributária, o que forneceu o escorço teórico para o objetivo primordial da argumentação, que seria o de validar a finalidade extrafiscal do IP. Para se confirmar as hipóteses expostas, recorreu-se à pesquisa exploratória, com a utilização do método hipotético-dedutivo.

\section{O TRIBUTO COMO MECANISMO DE INTERVENÇÃO DO ESTADO NA ECONOMIA}

Neste tópico expõe-se acerca da dinâmica de mercado ante a atuação ou a omissão do Estado na economia. Deve ser salientada a tradição clássica, doutrina segundo a qual o crescimento econômico prescinde às políticas de estabilização dos ciclos econômicos em detrimento à escola keynesiana, cujas políticas monetárias e fiscais são imprescindíveis ao crescimento econômico (SAMUELSON; NORDHAUS, 2004, p. 564). 
Para melhor elucidar o mecanismo de intervenção do Estado na economia, apresenta-se, inicialmente, o conceito da atividade financeira do Estado traduzido na obtenção de recursos econômicos e financeiros para o desempenho de suas atividades, principalmente via tributação. Esta premissa representa o modelo de Estado liberal, cuja atividade financeira restringe-se à cobertura dos dispêndios gerados pela máquina administrativa. O referido modelo, todavia, demonstrou-se incapaz de apontar soluções para a crise econômica decorrente da quebra da bolsa de Nova York em 1929, o que levou à adoção do modelo keynesiano de intervenção do Estado na Economia (FERRAZ; GODOI; SPAGNOL, 2017, p. 21). Neste modelo, o objeto da tributação extrapola a simples função arrecadatória e passa a contemplar a possibilidade de intervenção no domínio econômico.

É importante salientar a diferenciação de França $(2009$, p. 6) entre a intervenção do Estado no domínio econômico e a intervenção do Estado sobre o domínio econômico. No primeiro termo, o Estado assume um papel de agente econômico, controlando e gerindo, total ou parcialmente, os meios de produção e/ou troca essenciais a uma atividade econômica em sentido estrito determinada. O segundo, mais assemelhado ao objeto de estudo deste trabalho, encontra-se associado ao papel normativo do Estado, que pressupõe a imposição de comportamentos aos agentes econômicos privados para a concretização da finalidade político-econômica abrigada na Constituição Federal. Nesse aspecto, o autor menciona a seguinte classificação (FRANÇA, 2009, p. 6):

(a) intervenção por direção, quando o Estado exerce pressão sobre a economia, estabelecendo mecanismos e normas de comportamento compulsório para os sujeitos da atividade econômica em sentido estrito, através de normas diretivas;

(b) intervenção por indução, quando o Estado manipula os instrumentos de intervenção em consonância e na conformidade das leis que regem o funcionamento dos mercados, mediante normas de indução.

O IPI representa, no caso concreto, a possibilidade de intervenção econômica por meio da edição de ato normativo, conforme supraexposto. Isto porque, nas palavras de Paulsen e Melo (2013, p. 93), a Constituição Federal, em artigo 153, § 1을 atenua a legalidade tributária estrita do IPI ao facultar ao Poder Executivo a alteração das alíquotas sem a intermediação do Congresso Nacional. Na verdade, este constitui um dos mecanismos empregados pela política fiscal, no qual o governo, com a finalidade de estimular a atividade econômica, reduz os impostos que, associados à elevação da renda disponível, podem expandir o consumo pessoal e, consequentemente, a demanda global (MENDES, 2009, p. 178). Objetiva-se, então, o equilíbrio dos bens e recursos, os quais, em perfeita alocação, alcançam o "Equilíbrio Geral", obtendo-se a satisfação dos desejos e necessidades dos indivíduos, conciliados por meio da oferta e da demanda (RIANI, 2016, p. 6).

Em contraposição à teoria clássica, segundo a qual "a oferta cria a sua própria procura" (KEYNES, 1973, p. 15), o economista instituiu o postulado de que o nível de emprego em uma economia depende da demanda efetiva, ou seja, da proporção da renda gasta em consumo e investimentos. Em suma, ao Estado como regulador máximo da economia compete, por mecanismos de incentivo, realizar investimentos públicos com viés social, que gerem emprego e renda, de modo a garantir um ciclo virtuoso de crescimento (FERRAZ; GODOI; SPAGNOL, 2017, p. 24).

Para o estudo em tela, é evidente a intervenção estatal por meio da alteração das alíquotas dos impostos, cuja redução visa, em primeiro momento, a desonerar a cadeia produtiva, criando um estímulo à produtividade de determinado setor. A principal consequência, além da geração de emprego, é o aumento da oferta, a qual, em razão da queda no valor do produto ao consumidor, eleva também a procura, de modo que oferta e demanda estejam em pleno equilíbrio. Em sentido contrário, o Estado pode atuar quando almeja desestimular o consumo de determinados produtos. Nestes casos, a elevação da tributação mostra-se eficiente no sentido de inibir a produtividade, promovendo-se a respectiva queda no consumo, em face da elevação do produto final.

\subsection{0 conceito de Estado intervencionista}

Ferrari (2016, p. 15) define a intervenção estatal como "atuação em área de outrem", ou seja, em área cuja titularidade de exploração cabe, precipuamente, ao setor privado. A falência do liberalismo, fundado na premissa do laissez-faire, ensejou a necessidade de intervenção do Estado em vários setores para prover as necessidades da população. Neste contexto, o Estado de Bem-estar controla, estabelece limites e impõe dire- 
trizes à iniciativa privada. e se coloca como distribuidor com o intuito de auxiliar e amparar os menos favorecidos economicamente. De acordo com Silveira Neto (2014, p. 46), a intervenção no domínio econômico pode assumir as mais variadas formas, conforme elencadas a seguir:

(i) diretamente, por meio de suas empresas públicas, como é o caso da Petrobrás ou do Banco do Brasil. Nesse caso, para alcançar mais rapidamente objetivos de política econômica, o Estado, ao invés de esperar que o setor privado naturalmente ocupe espaços econômicos importantes, antecipa-se a isso e diretamente o faz;

(ii) indiretamente, por meio da regulação dos mercados. Nesse caso, enxergando que o mercado, desde que estimulado, pode rapidamente ocupar determinados espaços econômicos, o Estado, via disciplina jurídica do ambiente econômico, induz o setor privado a tomar determinadas ações. Ou ainda;

(iii) por meio da sua atividade financeira, mais precisamente, por meio do manejo direcionado da relação arrecadação-orçamento-dispêndio. Nesse caso, as finanças públicas do Estado não se limitam somente a cumprir suas funções burocráticas junto à sociedade, mas também a agir sobre o domínio econômico, mais especificamente sobre o setor privado, com o escopo de direcioná-lo ao alcance do bem comum.

O presente estudo abrange as funções regulatórias e regulamentares do Estado, detalhadas no item (ii) da citação anterior. A primeira função inclui a utilização dos mecanismos da macroeconomia, a exemplo da "lei de oferta e de procura", para promover a correção das distorções de mercado, enquanto a segunda restringe-se à edição de leis ou atos normativos em geral, sendo abordado, neste estudo, a edição de decretos do Poder Executivo com vistas à alteração da alíquota do IPI.

As formas de intervenção do Estado na economia, apontadas anteriormente, servem para elidir as faIhas do sistema de mercado, assim elencadas por Riani (2016, p. 28):

Indivisibilidade do produto: classificados como bens puros, por suas características só podem ser oferecidos pelo governo;

custos de produção decrescentes e mercados imperfeitos: economias de escala, que promovem o decréscimo do custo de produção, e consequentemente a concentração de mercado (oligopólio, monopólio e competição monopolística);

riscos e incertezas na oferta dos bens: decorre da falta de conhecimento do mercado, e, por conseguinte, a dificuldade de se obter alocação ótima de acordo com a preferência da sociedade e os interesses dos produtores.

Vasconcellos (2015, p. 104) acrescenta ainda, ao rol das falhas de mercado, a externalidade: quando o consumo ou a produção de determinado bem ou serviço produz efeitos colaterais, gerando custos superiores aos benefícios. Em virtude das falhas de mercado, conforme detalhamento supra, o Estado dispõe de mecanismos para amenizá-las e, por conseguinte, alcançar maior nível de bem-estar à população. Considerando-se o escopo do presente trabalho, relativo à intervenção do Estado na economia por meio da atividade financeira, passa-se à análise do Estado intervencionista, com ênfase nas funções alocativa, distributiva e estabilizadora, consideradas como a base da teoria econômica clássica do tributo (FALCÃO, 2012, p. 125).

\subsection{A função alocativa}

Segundo Vasconcellos (2015, p. 410), a função alocativa do governo está associada ao fornecimento de bens e serviços não oferecidos adequadamente pelo sistema de mercado na produção ou consumo de certos bens e serviços. Esta função do governo atua, sobretudo, no mercado de bens públicos, aqueles indivisíveis.

Além de assumir o mercado de bens e serviços, cuja indivisibilidade dos produtos inviabilize os investimentos do setor privado, Riani (2016, p. 28) enumera formas pelas quais o governo assegura a alocação dos recursos de forma indireta, ou seja, induzindo a oferta pelo setor privado:

- o governo poderá alocar diretamente recursos na produção e oferta dos bens. Por exemplo, os serviços de defesa nacional e segurança pública são os mais próximos desse caso;

- o governo poderá adquirir os produtos de empresas privadas e oferecê-los à sociedade. Exemplo: medicamentos, merenda escolar, etc.; 
- através de subsídios e incentivos diversos o governo poderá induzir o setor privado a investir recursos na produção, o que não aconteceria sem a sua interferência. Nesses casos os bens e serviços seriam produzidos e vendidos no mercado pelo setor privado; e- o governo poderá investir recursos na instalação de empresas públicas com o objetivo de gerar e/ou produzir bens e serviços necessários e não oferecidos pelo setor privado. Esses casos enquadram-se na produção de bens econômicos por parte do governo, ou seja, esses bens seriam vendidos no mercado.

Na realidade, a utilização de decreto para alterar a alíquota do IPI, por parte do Poder Executivo, não se enquadra em nenhuma das hipóteses anteriormente arroladas, porquanto, não obstante este mecanismo ser considerado uma forma de intervenção do Estado na economia, caracteriza-se pela interferência indireta, analisando-se as referidas hipóteses.

Ademais, a função alocativa do Estado pode ser ampliada para abranger a função distributiva (trabalhada no tópico a seguir) nos seguintes moldes: externa (ou política), por meio de políticas sociais voltadas aos segmentos assistidos, e interna (ou administrativa), que se executa por intermédio dos orçamentos públicos, na distribuição dos meios financeiros entre entes e órgãos (MOREIRA NETO, 2005, p. 15).

No que diz respeito à execução do orçamento, pode o Estado diminuir a alíquota de determinado imposto, renunciando à receita, para estimular o segmento produtivo que alcance parcela menos favorecida da população em detrimento àquela de maior poder aquisitivo. No sentido inverso, o Estado pode promover a justiça social, aumentando a alíquota de determinado imposto, cuja incidência seja em desfavor de certo setor produtivo, composto por parcela privilegiada da população.

\subsection{A função redistributiva}

Vasconcellos (2015, p. 321) acentua a política fiscal como um dos principais mecanismos do governo para promover a distribuição de renda. Todavia, a premissa supracitada, todavia, pode aparentar um paradoxo, uma vez que "não somos habituados a considerar o Estado como distribuidor de riqueza entre os seus cidadãos, mas como um distribuidor de encargos, em forma de tributação".

Em que pese suposta contradição, ante o caráter oneroso dos tributos em desfavor do contribuinte, na atualidade o governo tem se utilizado da política fiscal para promover os princípios da justiça distributiva e da igualdade, por meio da análise da capacidade econômica do contribuinte como critério para graduação das alíquotas. Assim estabelece o artigo 145, § 1ำ da Constituição Federal (BRASIL, 2017):

Art. 145. A União, os Estados, o Distrito Federal e os Municípios poderão instituir os seguintes tributos:

I-impostos;

II - taxas, em razão do exercício do poder de polícia ou pela utilização, efetiva ou potencial, de serviços públicos específicos e divisíveis, prestados ao contribuinte ou postos a sua disposição;

III - contribuição de melhoria, decorrente de obras públicas.

$\S 1$ 을 Sempre que possível, os impostos terão caráter pessoal e serão graduados segundo a capacidade econômica do contribuinte, facultado à administração tributária, especialmente para conferir efetividade a esses objetivos, identificar, respeitados os direitos individuais e nos termos da lei, o patrimônio, os rendimentos e as atividades econômicas do contribuinte.

Sobre o assunto em tela, Yamashita $(2014$, p. 54) afirma que a Constituição Federal não somente proibiu certos critérios de comparação, mas também elegeu, segundo dispositivo supracitado, como critério de comparação a capacidade contributiva, a qual também se ampara no princípio constitucional do Estado Social, que garante a cada cidadão o mínimo existencial, seja transferindo aos cidadãos necessitados os recursos que eles precisam para a existência, seja como Estado Tributário, deixando aos contribuintes pelo menos um mínimo existencial. Na prática, Riani (2016, p. 38) elenca algumas formas pelas quais o Estado aplica sua função redistribuidora, quando: destina as cargas tributárias mais elevadas para as camadas mais ricas da sociedade; cria mecanismos adequados de transferências de renda pessoal e regional; institui subsídios e incentivos que diminuem o custo de acesso a certos bens e serviços; cria leis regulatórias de proteção a um salário mínimo de subsistência; dá proteção tarifária e aplica gastos públicos em atividades que permitam a utilização dos bens e serviços por uma camada da sociedade carente de recursos para obter esses bens no mercado privado. 
O mercado automotivo constitui um importante exemplo da distribuição de renda promovida pelo Estado. A redução da alíquota do IPI produz um efeito cascata, quando desonera os meios de produção e diminui o preço final ao consumidor. Nesse sentido, aumentam-se as possibilidades de as classes média e baixa adquirirem um veículo.

\subsection{A função estabilizadora}

A função estabilizadora utiliza-se dos instrumentos macroeconômicos para manter certo grau de utilização dos recursos e estabilizar o valor da moeda. Segundo Vasconcellos (2015, p. 322), objetiva-se alterar o comportamento dos níveis de preços e emprego, pois o pleno emprego e a estabilidade dos preços não ocorrem de maneira automática na economia.

Riani (2016, p. 39) ressalta a relevância desta função em períodos de crise econômica, porquanto, quando o desemprego prevalece, o governo aumenta a demanda no mercado, elevando seus gastos ou diminuindo seus tributos, realocando a produção no pleno emprego. Por outro lado, se há inflação, o governo pode reduzir o patamar da demanda no mercado, ajustando seus gastos e tributos, reduzindo assim a demanda e os preços.

Esta função foi objeto do estudo empírico de Salomão (2014, p. 47), o qual discorreu acerca da intervenção estatal em momento de crise econômica no período de 2008 a 2013, quando, visando a alavancar a indústria automobilística no Brasil, importante segmento produtivo no cenário econômico nacional, reduziu-se a alíquota do IPI. Como resultado da desoneração tributária, demonstrou-se, por meio de dados estatísticos, que a redução nos custos de produção elevou a demanda por veículos, e, no plano macroeconômico, garantiu a manutenção de cerca de 1,5 milhões de vagas de trabalho diretas, assim como a manutenção de um setor que representa 6,5\% de todo o Produto Interno Bruto brasileiro.

\section{OS OBJETIVOS DA EXTRAFISCALIDADE E DA SELETIVIDADE TRIBUTÁRIA}

Decorridas as análises concernentes à função precípua da política fiscal de arrecadação de recursos em face das despesas da máquina administrativa, propõe-se a apreciação do caráter extrafiscal do tributo, em razão da essencialidade do produto sobre o qual incide o ônus. De acordo com Ferraz, Godoi e Spagnol (2017, p. 21), a função arrecadatória pode ser relegada a segundo plano quando o objetivo for induzir o comportamento do particular, a exemplo do ITR progressivo para propriedades improdutivas, ou o controle da atividade econômica, exemplificado pelo aumento da alíquota do IOF para conter uma explosão de consumo.

O caráter extrafiscal inerente a determinados tributos tem amparo constitucional no artigo $153, \S 1$. $\mathrm{Na}$ verdade, excepciona-se à participação do Congresso Nacional na alteração da alíquota, concedendo ao chefe do Poder Executivo autonomia para fixá-la por meio de decreto. A Constituição Federal, neste aspecto, flexibilizou os princípios da legalidade e da anterioridade, atribuídos aos tributos. Segue citação do referido dispositivo constitucional (BRASIL, 2017):

Art. 153. Compete à União instituir impostos sobre:

I- importação de produtos estrangeiros;

II - exportação, para o exterior, de produtos nacionais ou nacionalizados;

III - renda e proventos de qualquer natureza;

IV - produtos industrializados;

V - operações de crédito, câmbio e seguro, ou relativas a títulos ou valores mobiliários;

$\mathrm{VI}$ - propriedade territorial rural;

$\mathrm{VII}$ - grandes fortunas, nos termos de lei complementar.

$\S 10$ É facultado ao Poder Executivo, atendidas as condições e os limites estabelecidos em lei, alterar as alíquotas dos impostos enumerados nos incisos I, II, IV e V. 
Diante do exposto, salienta-se o motivo pelo qual a Constituição Federal concede a extrafiscalidade a alguns impostos: o princípio da seletividade, também estabelecido na Constituição Federal, no seu artigo 153, $\S 3$, inciso I, conforme segue (BRASIL, 2017):

Art. 153. Compete à União instituir impostos sobre:

$[\ldots]$

IV - produtos industrializados;

$[\ldots]$

$\S 3$ ○ O imposto previsto no inciso IV:

I - será seletivo, em função da essencialidade do produto;

$[\ldots]$.

A seletividade leva à aplicação de alíquotas diferenciadas segundo o tipo de produto objeto da tributação. O critério utilizado para a escolha das alíquotas foi fixado pelo artigo 153, § 3, inciso I da Constituição Federal (supramencionado), a saber, a essencialidade do produto. Conforme estudado anteriormente, na função redistributiva do Estado o princípio da seletividade atende ao princípio da capacidade contributiva quando onera a carga tributária de produtos supérfluos (adquiridos por consumidores de maior poder aquisitivo) e minimiza os efeitos da tributação sobre produtos indispensáveis/essenciais aos indivíduos de baixa capacidade contributiva (PAULSEN; MELO, 2013).

Evidencia-se, assim, a classificação dos produtos cujas alíquotas podem ser aplicadas consoante o princípio da seletividade (VALLE, 2013).

a) bens de primeira necessidade, dos quais precisam todos, mas que são os únicos produtos ao alcance daqueles que se mantêm no nível mínimo de subsistência; b) bens não necessários, que são consumidos por um número bastante grande de pessoas, que vivem em diversos graus de escala econômica, porém todos acima do nível mais baixo; c) artigos de luxo, disponíveis, principalmente, para as pessoas em nível mais elevado de bem-estar.

Além de considerar a capacidade do contribuinte, a extrafiscalidade e a seletividade são mecanismos estimuladores ou inibidores de comportamento (consumo). Neste ponto, Paulsen e Melo (2013) mencionam a tributação dos cigarros, cujo objetivo é desestimular o consumo por motivos de saúde. Vale mencionar, no sentido contrário, a redução da alíquota do IPI, incidente sobre veículos automotores, no intuito de elevar o consumo.

\section{A FINALIDADE EXTRAFISCAL E SELETIVA DO IMPOSTO SOBRE PRODUTOS INDUSTRIALIZADOS}

Superada a análise geral acerca da intervenção do Estado na economia, aborda-se, na presente seção, o Imposto sobre Produtos Industrializados, sob a perspectiva empírica.

Segundo Ribeiro (2013, p. 123), o IPI constitui imposto de competência federal, e sua existência remonta à Constituição de 1934, a qual foi também estabelecida na Constituição Federal de 1988, no artigo 153, inciso IV, com os acréscimos no § 3으, introduzidos pela Emenda Constitucional EC $n=42 / 03$. Além da Constituição Federal, menciona-se a legislação correlata ao IPI, a saber, Lei no 4.502/1964 (lei instituidora), artigos 46 a 51 da Código Tributário Nacional, os quais estabelecem normas gerais do tributo, e Decreto no 7.212/2010, que regulamenta a cobrança, fiscalização, arrecadação e administração do imposto.

A seguir, tem-se a apreciação do IPI sob o enfoque da regra matriz de incidência tributária, na qual se adotam os critérios da hipótese (material e espacial) e da consequência (sujeitos ativo/passivo e quantitativo - base de cálculo e alíquota).

No que concerne ao critério material, relativo ao fato que enseja a incidência do IPI, evidencia-se que o mesmo recai sobre qualquer produto decorrente do processo de industrialização, mencionando-se, neste contexto, os dizeres de Paulsen e Melo (2013, p. 90), que, assim, delimitaram a incidência do imposto: 
[...] o IPI incide nas operações de que participa o industrial que industrializou o produto, mas não na venda por comerciante ao consumidor. Não basta, portanto, que o produto objeto do negócio jurídico tenha sido industrializado em algum momento, mas que se tribute a própria produção quando ela acontece. Na venda de produto por comerciante, temos apenas o comércio, a circulação de mercadoria. A fase de produção, de industrialização, é anterior.

O critério espacial, pertinente ao local onde ocorreu o fato supradescrito, encontra-se evidenciado no caput do artigo 153 da Constituição Federal, o qual estabelece que "compete à União instituir impostos [...]", que arrola no inciso IV o IPI, presumindo-se que incide o IPI sobre o fato gerador ocorrido no território da União. Ademais, o artigo 46 do CTN descreve o momento segundo o qual há incidência da exação em comento:

Art. 46. O imposto, de competência da União, sobre produtos industrializados tem como fato gerador:

1 - o seu desembaraço aduaneiro, quando de procedência estrangeira;

II - a sua saída dos estabelecimentos a que se refere o parágrafo único do artigo 51;

III - a sua arrematação, quando apreendido ou abandonado e levado a leilão.

Parágrafo único. Para os efeitos deste imposto, considera-se industrializado o produto que tenha sido submetido a qualquer operação que the modifique a natureza ou a finalidade, ou o aperfeiçoe para o consumo.

No que diz respeito aos critérios de consequência, quais sejam, sujeitos ativo e passivo, considera-se sujeito ativo a União, que institui e fiscaliza a cobrança do imposto por meio de seus órgãos e, sujeito passivo, o contribuinte, pois sobre este recai o ônus da tributação. Neste sentido, o artigo 51 do CTN enumera em rol taxativo os contribuintes do IPI:

Art. 51. Contribuinte do imposto é:

I - o importador ou quem a lei a ele equiparar;

II - o industrial ou quem a lei a ele equiparar;

III - o comerciante de produtos sujeitos ao imposto, que os forneça aos contribuintes definidos no inciso anterior;

IV - o arrematante de produtos apreendidos ou abandonados, levados a leilão.

Parágrafo único. Para os efeitos deste imposto, considera-se contribuinte autônomo qualquer estabelecimento de importador, industrial, comerciante ou arrematante (BRASIL, 2017).

Por fim, também incluído nos critérios de consequência, menciona-se o aspecto quantitativo do tributo, sobre o qual advém a base de cálculo e a alíquota. Sobre o primeiro, a base de cálculo, o artigo 47 do CTN estabelece-o em rol taxativo; o segundo, atinente à alíquota, conforme mencionado exaustivamente no decorrer deste estudo, estabelece-se por meio de Decreto, emitido pelo chefe do Poder Executivo, o que não obsta a fixação pelas vias ordinárias, ou seja, pelo Poder Legislativo.

Art. 47. A base de cálculo do imposto é:

I - no caso do inciso I do artigo anterior, o preço normal, como definido no inciso II do artigo 20, acrescido do montante:

a) do imposto sobre a importação;

b) das taxas exigidas para entrada do produto no País;

c) dos encargos cambiais efetivamente pagos pelo importador ou dele exigíveis;

II - no caso do inciso II do artigo anterior:

a) o valor da operação de que decorrer a saída da mercadoria;

b) na falta do valor a que se refere a alínea anterior, o preço corrente da mercadoria, ou sua similar, no mercado atacadista da praça do remetente;

III - no caso do inciso III do artigo anterior, o preço da arrematação.

Dadas as considerações iniciais pertinentes ao IPI, procede-se a análise das peculiaridades deste imposto, ante a possibilidade de intervenção do Estado na Economia. 


\subsection{O IPI como Instrumento de Intervenção do Estado na Economia}

O IPI excepciona-se ao princípio da anterioridade de exercício intrínseco à maioria dos impostos, porque permite a cobrança do imposto no mesmo exercício em que foi editada a Lei que alterou sua alíquota. Este é o caráter extrafiscal do tributo, ao qual Torres $(2007$, p. 177) atribui a responsabilidade pela regulação do mercado, pelo desenvolvimento de certas atividades e pela inibição de consumos.

Assim, a exceção ao princípio da anterioridade, associada à mitigação ao princípio da legalidade, a qual concede, ao chefe do Poder Executivo, a faculdade de alterar a alíquota do IPI sem a participação do Congresso Nacional, constituem fatores que possibilitam a interferência do Estado na produção econômica, na medida em que estimulam ou inibem o consumo de determinados produtos.

No âmbito jurídico, o caráter extrafiscal do IPI compõe o Estado Democrático de Direito eleito na Constituição Federal, a qual estabelece valores e objetivos que necessitam ser instituídos por meio de políticas públicas. Neste contexto, a tributação é um instrumento por meio do qual o Estado concretiza as diretrizes constitucionais.

No contexto econômico, a explanação de Chiesa (2013, p. 187) evidencia a função extrafiscal do tributo como instrumento de intervenção na economia:

A extrafiscalidade, portanto, caracteriza-se pelo uso de instrumentos jurídicos-tributários para induzir comportamentos, estimulando-os ou os desestimulando, detendo o agente político liberdade de escolha sobre o modo como irá utilizá-los e sobre quais valores postos na Constituição pretenderá realizar ou implementar, por meio da tributação, desde que não seja o valor "essencialidade", já que para este não há liberdade para o Estado implantar ou não uma política fiscal seletiva, mas imposição da Constituição que seja realizada pela seletividade.

Da citação supra depreende-se que a seletividade é um princípio norteador, e se sujeita o IPI, especialmente quando considerado na função extrafiscal. Isso porque quando o Poder Executivo exerce a faculdade de alteração das alíquotas do IPI, o faz em razão da essencialidade dos produtos.

\subsection{Análise Jurídica do IPI sob os aspectos da extrafiscalidade e da seletividade}

No presente subtítulo evidencia-se o caráter extrafiscal do IPI à luz do princípio da seletividade, transpondo-a para os segmentos "veículos" e "tabaco", com o escopo de demonstrar, de forma quantitativa, a relevância destes produtos no mercado de consumo brasileiro.

Para o estudo em tela, a abordagem de séries históricas, relacionadas à aquisição de veículos e tabaco, é estratégica. Quanto ao primeiro - veículos -, evidencia-se o estudo de Salomão (2014, p. 20), segundo o qual o mercado automotor foi objeto de interferência do governo no período da crise de 2008 , em razão de sua relevância na economia brasileira, por representar um percentual de 6,5\% do Produto Interno Bruto brasileiro. Nesse contexto, o mencionado autor enumerou os impactos da crise econômica no setor automotivo, quais sejam:

(i) a redução na concessão de créditos, devido à instabilidade macroeconômica mundial, dificultando, dessa forma, o financiamento de automóveis; e (ii) o aumento do dólar, fator que elevou o valor do automóvel importado, além de indiretamente, elevar o valor do automóvel nacional. Segundo o site GLOBO.COM, "o câmbio, que estava em cerca de $R \$ 1,60$ em agosto de 2008, chegou cerca de $R \$ 2,40$ em dezembro do mesmo ano". Diante da crise no mercado, o setor automotivo necessitava de uma ação governamental para evitar o colapso.

A segunda abordagem, no segmento do tabaco, traz uma clara representação do princípio da seletividade, cujo critério para a escolha da alíquota do IPI, por parte do chefe do Poder Executivo, é a essencialidade do produto. Neste aspecto, é importante ampliar o conceito de essencialidade do produto associado à perspectiva da elasticidade-preço condicionada às variações da carga tributária (VASQUES, 2005):

Se o aumento percentual no preço de um bem provoca uma quebra percentualmente superior na quantidade procurada, diz-se que a procura é elástica - significa isso que, dentro de certo intervalo, qualquer aumento do preço induzido pelo imposto tem como resultado último a diminuição na receita angariada. Se o aumento per- 
centual no preço de um bem provoca uma quebra percentualmente idêntica na quantidade procurada, a elasticidade da procura diz-se unitária, significando isso que dentro de certo intervalo, a receita tributária se mantém a mesma, qualquer que seja o peso do imposto. Se o aumento percentual no preço de um bem provoca uma quebra percentualmente inferior na quantidade procurada, a procura diz-se rígida. Significa isso que dentro de certo intervalo qualquer aumento do preço induzido pelo imposto gera um aumento da receita angariada.

Ainda, quanto aos efeitos da tributação seletiva, Vasques (2005) reforça que "os impostos especiais de consumo podem rever um caráter predatório do bem, podendo o legislador voltar-se contra os hábitos de consumo a que os contribuintes não podem escapar". Aplica-se esta questão ao caso do tabaco, uma vez já conhecidos os efeitos nocivos deste aos usuários. Outro exemplo prático seria aquele aludido por Samuelson e Nordhaus (2004, p. 272), quando consideram a possibilidade de utilizar-se do mecanismo da tributação para conter externalidades indesejáveis, a exemplo da aplicação de um "imposto sobre o carbono", visando à redução da emissão de gases.

Além da essencialidade, há de se ponderar a elasticidade dos produtos na escolha do mercado, que se constituirá objeto da política econômica, ou seja, é mais conveniente a escolha daqueles bens considerados mais elásticos. A elasticidade, termo utilizado nas ciências econômicas, muito se assemelha ao princípio da seletividade. Este analisa o produto sob a perspectiva de sua essencialidade, ou seja, os produtos imprescindíveis, a exemplo dos remédios, que não podem ter suas alíquotas majoradas, ao contrário das bebidas, cigarros e refrigerantes, que, por não serem essenciais, devem ter suas cargas tributárias aumentadas para, inclusive, desestimular o consumo. Neste ponto, Coêlho $(2008$, p. 507) frisa que o legislador não é apto a declarar a essencialidade ou não essencialidade de determinado produto. Não compete ao Poder Legislativo a fixação de alíquota. Neste caso, a responsabilidade recai sobre o Poder Executivo, o qual, dentro dos limites fixados em lei e por meio de ato administrativo, determina o percentual de incidência do IPI. Esta atribuição ao chefe do Executivo, concedida pela Constituição e pelo CTN, foi instituída para viabilizar o ajuste da política industrial do país.

No tocante à elasticidade, convém salientar a premissa estabelecida por Wessels (2010, p. 456), segundo a qual "a carga da tributação cai sobre aqueles cuja demanda ou oferta for mais inelástica". A carga tributária incidente sobre o mercado imobiliário, sobretudo propriedades rurais, exemplifica perfeitamente esta tese, uma vez que as interferências neste mercado não produzem mudanças imediatas quando comparadas aos efeitos no mercado de bens e serviços.

Em sentido inverso à mencionada premissa, a extrafiscalidade do IPI é mais utilizada quando se trata de produtos mais elásticos, ou seja, aqueles cuja reação dos consumidores às variações do preço final, seja maior. Em outras palavras, quando se adota uma política econômica expansionista, com o objetivo de geração de emprego, produto e renda, a diminuição da carga tributária desonera todo o ciclo produtivo, viabilizando o consumo em razão da queda do preço no bem final. Como consequência da expansão da demanda, exige-se do fornecedor maiores quantidades de produtos, forçando um acréscimo na mão de obra, alterando-se o cenário econômico naquele segmento produtivo no qual houve intervenção direta do Estado.

\subsection{Uma análise empírica sobre o consumo do álcool, do tabaco e de veículos a partir da perspectiva seletiva e extrafiscal do IPI}

Dadas as exposições teóricas acerca da extrafiscalidade e seletividade do IPI, apostos ao mercado de veículos e tabaco, propõe-se, nesta seção, a análise quantitativa destes mercados, demonstrando-se, por meio de dados estatísticos, os efeitos da aplicação dos mecanismos de intervenção do Estado na economia. Dessa forma, seguem os subtópicos "veículos" e "tabaco".

\subsubsection{O segmento de veículos}

Conforme mencionado no decorrer deste trabalho, o mercado automobilístico compõe um importante setor da economia brasileira, tanto na composição do PIB quanto na geração de emprego e renda. Isso explica as inúmeras medidas executadas pelo governo federal com vistas à alavancagem do setor. Nesse sentido, considerando-se o período abordado, de 2010 a 2015, o Poder Executivo alterou inúmeras vezes a alíquota do IPI, mediante decreto que estabeleceu as alíquotas de IPI incidentes sobre determinados produtos, os quais recebem uma classificação numérica na Tabela de Incidência do Imposto sobre Produtos Industrializados (Tipi). 
A citada tabela classifica os "Automóveis de passageiros e outros veículos automóveis principalmente concebidos para transporte de pessoas, incluindo os veículos de uso misto e os automóveis de corrida", no código 8703. Este código se subdivide consoante as particularidades do automóvel. Como objeto para análise deste trabalho, toma-se como parâmetro o código 8703.21.00, relativo aos automóveis de passageiros cujas cilindradas não sejam superiores a mil centímetros cúbicos, popularmente conhecidos como carros de motor 1.0.

Esta escolha é didática e visa a se compatibilizar com os dados dos "emplacamentos" de veículos disponibilizados pela Federação Nacional da Distribuição de Veículos Automotores - Fenabrave, que assim classifica os veículos: A) Autos; B) Com. Leves; C) Caminhões; D) Ônibus; E) Motos; F) Impl. Rod.; Outros; e Máq. Agrícolas.

Embora se tenha observado, no período analisado, que as alterações das alíquotas do IPI, incidiram na mesma proporcionalidade sobre os veículos cuja potência do motor seja superior a 1.0 (classificados no código 8703.22 da TIPI como automóveis cuja cilindrada seja superior a 1.000 centímetros cúbicos, mas não superior a 1.500 centímetros cúbicos), o presente estudo restringe-se aos veículos classificados no código 8703.21.00, por corresponderem aos dados de emplacamentos da Fenabrave, classificados no item A) Autos.

Desse modo, segue o histórico de variação da alíquota do IPI do período de 2010 a 2015, cujos dados, pertinentes às alíquotas, advêm das informações contidas no trabalho de Salomão (2014, p. 22-29); do levantamento dos Decretos editados pelo Presidente da República bem como das notícias veiculadas por meio do portal da GLOBO.COM.

As variações das alíquotas do IPI, incidentes sobre os veículos classificados no código 8703.21.00, serão demonstradas primeiramente na Tabela 1, quando se discrimina o período com a respectiva alíquota vigente, e, posteriormente, o Gráfico 1 expõe os mesmos valores em forma de figura, de modo a facilitar a visualização das variações ao leitor.

Tabela 1 - Percentual de IPI incidente sobre veículos classificados no código 8703.21.00 da Tipi, do período de 2010 a 2015

\begin{tabular}{|l|c|}
\hline Período de vigência & Alíquota do IPI \\
\hline Janeiro, fevereiro e março de 2010 & $3 \%$ \\
\hline Abril a dezembro de 2010 & $7 \%$ \\
\hline Exercício de 2011 & $7 \%$ \\
\hline Maio a dezembro de 2012 & $0 \%$ \\
\hline Janeiro a dezembro de 2013 & $2 \%$ \\
\hline Exercício de 2014 & $3 \%$ \\
\hline Exercício de 2015 & $7 \%$ \\
\hline
\end{tabular}

Fonte: Salomão (2014, p. 22-29), Decretos do Poder Executivo (Palácio do Planalto, 2017) e notícias (GLOBO.COM, 2017 ).

Gráfico 1 - Percentual de IPI incidente sobre veículos classificados no código 8703.21.00 da Tipi, do período de 2010 a 2015

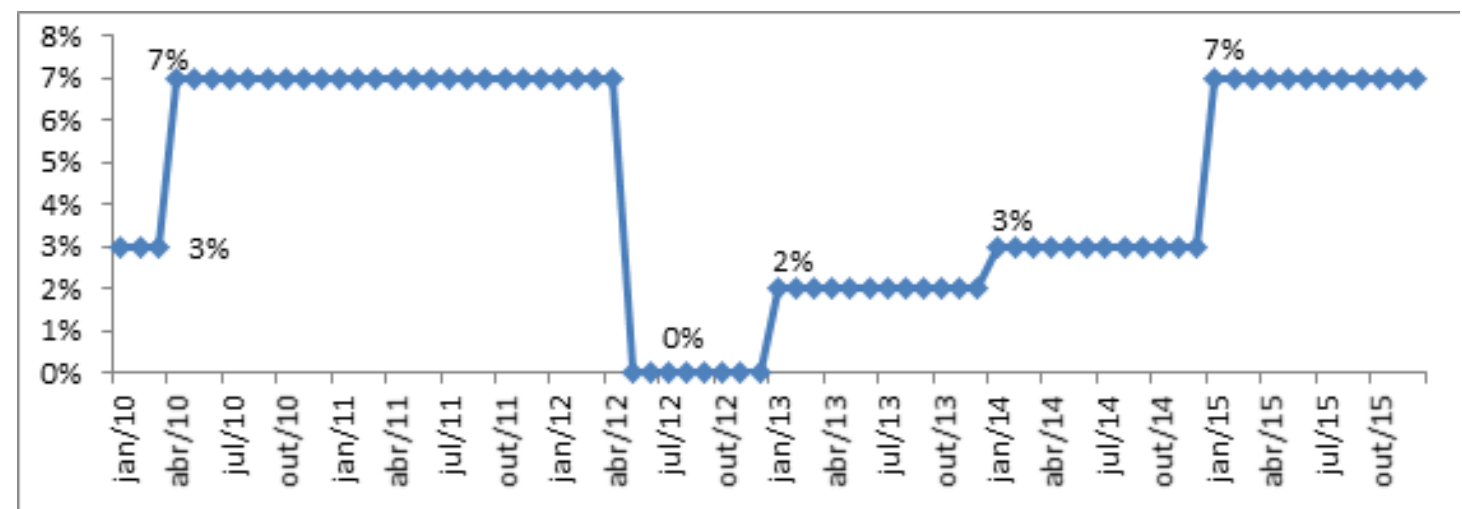

Fonte: Salomão (2014, p. 22-29); Decretos do Poder Executivo (Palácio do Planalto, 2017); e notícias (GLOBO.COM, 2017). 
Para se mensurar a efetividade das medidas adotadas pelo governo federal, confrontam-se os seguintes dados: alíquota do IPI vigente e emplacamentos de veículos, aplicando-se a seguinte metodologia:

De acordo com o Gráfico 1, depreende-se que os cinco anos adotados para análise podem ser divididos em seis grupos, consoante o percentual de IPI aplicado.

Tabela 2 - Percentual de IPI incidente sobre veículos classificados por Grupos

\begin{tabular}{|l|l|c|}
\hline Grupos & Período & Alíquota IPI \\
\hline GRUPO A & janeiro a março de 2010 & $3 \%$ \\
\hline GRUPO B & abril de 2010 a abril de 2012 & $7 \%$ \\
\hline GRUPO C & maio a dezembro de 2012 & $0 \%$ (isenção) \\
\hline GRUPO D & janeiro a dezembro de 2013 & $2 \%$ \\
\hline GRUPO E & janeiro a dezembro de 2014 & $3 \%$ \\
\hline GRUPO F & janeiro a dezembro de 2015 & $7 \%$ \\
\hline
\end{tabular}

Fonte: Salomão (2014, p. 22-29); Decretos do Poder Executivo (Palácio do Planalto, 2017); e notícias (GLOBO.COM, 2017).

Para os seis grupos será feita a média aritmética da quantidade de veículos emplacados, possibilitando-se a comparação entre os quantitativos de emplacamentos efetuados em razão de cada alíquota de IPI aplicada, conforme Gráfico 2, que segue.

Gráfico 2 - Quantitativo de veículos emplacados em razão das diferentes alíquotas de IPI aplicadas no período de 2010 a 2015

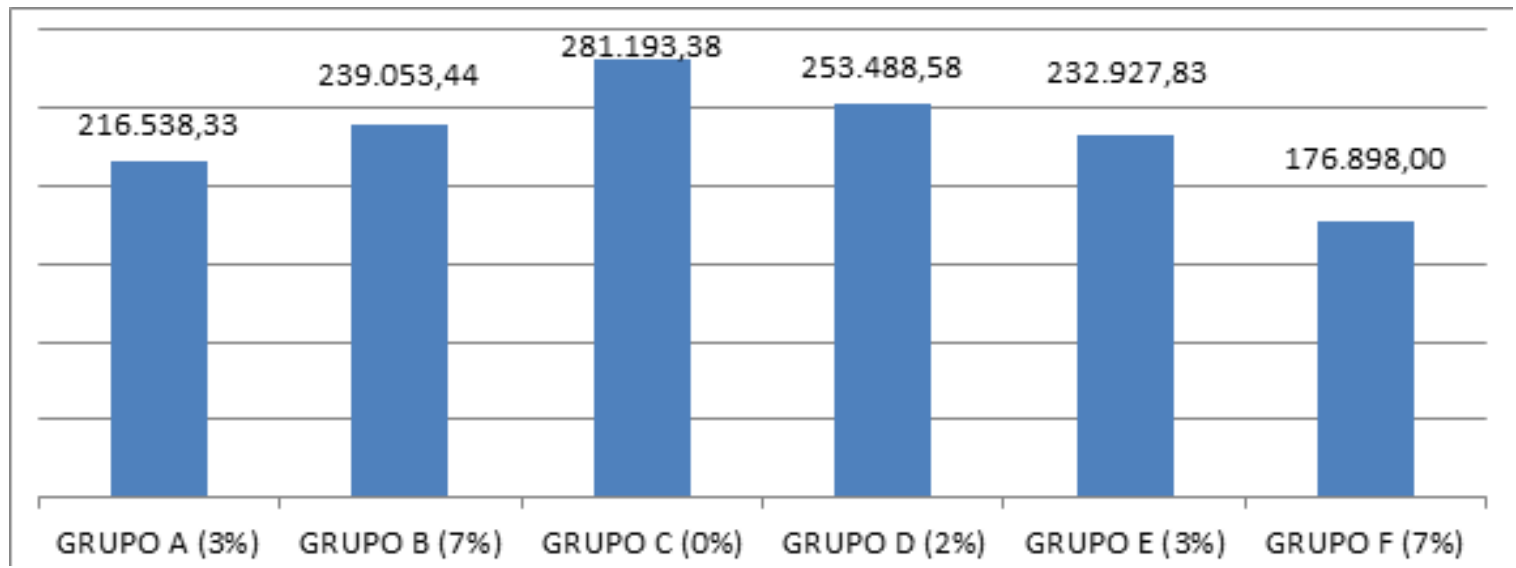

Fonte: FENABRAVE (2017).

No gráfico 2 avaliou-se as vendas de veículos em virtude das alterações da alíquota do IPI no período de 2010 a 2015, considerando-se constantes outras variáveis, como qualidade do produto e renda do consumidor, em latim Ceteris Paribus.

Da análise dos dados supra, depreende-se que a alíquota de IPI aplicada e a quantidade de veículos vendida, apresentaram-se inversamente proporcionais, ou seja, quanto menor a alíquota do IPI, maior o consumo de veículos, destacando-se o período no qual vigorou a isenção do IPI (alíquota 0\%), cujo consumo atingiu o ápice no período analisado (281.193,38 emplacamentos).

Excetua-se o Grupo A, no qual os resultados dos emplacamentos foram inferiores quando comparados aos outros grupos, cujas alíquotas foram superiores ao percentual de $3 \%$ aplicado ao Grupo A. Merece se considerar, todavia, o contexto no qual foi fixada essa alíquota de 3\%: até setembro de 2009, como resultado do Decreto no 6.809/09 prevalecia a isenção (0\%) de alíquotas do IPI em favor dos veículos zero mil cilindradas $\left(\mathrm{cm}^{3}\right)$, posto que, a partir de outubro, as alíquotas foram sendo ajustadas paulatinamente, chegando ao percentual de 3\% em janeiro de 2010. Para o período em questão, janeiro a março de 2010, portanto, a alíquota 
do IPI estava alta, quando comparada ao exercício anterior, 2009, cuja alíquota prevalecente entre janeiro a setembro foi de $0 \%$. Isso constituiu um fator psicológico que influenciou o comportamento do consumidor, desestimulando o consumo no período do Grupo A.

Em contrapartida, vale salientar o aumento do consumo no grupo seguinte, Grupo B, que, a despeito da alíquota de IPI elevada, de $7 \%$, o número de emplacamentos subiu num percentual de $9,41 \%$, comparado ao Grupo A. Neste contexto, a ausência de previsão para a redução das alíquotas de IPI estimulou o consumo daqueles que já tinham a intenção de adquirir um veículo.

Nos demais grupos, o aumento da procura por veículos, em decorrência da medida extrafiscal do governo de redução da alíquota do IPI, evidencia a elevada elasticidade dos veículos, que pode ser atribuída à essencialidade do bem. Neste ponto, o aumento da população, associado à respectiva expansão das cidades e à precariedade do sistema de transporte coletivo, tornam-se fatores imprescindíveis para a aquisição de veículo de uso particular, visando à maior mobilidade e à consequente autonomia aos indivíduos (LUZ et al., 2014, p. 395).

Diante do exposto, conclui-se que as ações do governo produziram resultados diretos e imediatos no mercado de veículos, porquanto, restou demonstrado, por meio de dados estatísticos, que a redução das alíquotas do IPI, por meio de decretos do Poder Executivo, elevou as vendas de veículos a patamares consideráveis, consoante a alíquota aplicada.

\subsubsection{O segmento do tabaco}

O tabaco constitui-se o principal insumo na produção de cigarros. Por este motivo, analisa-se, neste subitem, o consumo de cigarros ao longo do período de 2012 a 2016, em razão da alíquota de IPI incidente.

Convém salientar a adoção de período diferenciado daquele utilizado na análise do mercado consumidor de veículos, em virtude do advento da Lei $n$ o $12.546 / 11$, que estabeleceu novo regime de tributação a partir de dezembro de 2011, motivo pelo qual os dados da pesquisa abrangerão o período de 2012 a 2016.

O portal eletrônico do Instituto Nacional do Câncer - Inca (INCA, 2017), órgão auxiliar do Ministério da Saúde, assim diferencia os dois regimes de tributação instituídos - o geral e o especial:

A regra geral de tributação do IPI estabelece que o mesmo será calculado utilizando-se de uma alíquota ad valorem de $300 \%$ aplicada sobre $15 \%$ do preço de venda a varejo dos cigarros, resultando em uma alíquota efetiva de $45 \%$ sobre o preço de venda. A carga tributária total sobre os cigarros fica em $81 \%$, sendo $45 \%$ de IPI, $11 \%$ de PIS/Cofins e $26 \%$ de ICMS. Caso o fabricante ou importador de cigarros opte pelo regime especial de apuração e recolhimento do IPI, o valor do imposto será obtido pelo somatório de 2 (duas) parcelas, sendo um ad valorem, calculada da mesma forma que o regime geral, e outra específica, de acordo com o tipo de embalagem (maço ou box).

Na Tabela a seguir expõem-se as alíquotas do IPI aplicadas ao cigarro, discriminadas pelos dois regimes de tributação mencionados, do período de dezembro de 2011 a dezembro de 2016, de acordo com os dados da Receita Federal - Ministério da Fazenda.

Tabela 3 - Percentual de IPI incidente em cigarros no período de dezembro de 2011 a dezembro de 2016

\begin{tabular}{|c|c|c|c|}
\hline \multirow{3}{*}{ Vigência } & \multicolumn{3}{|c|}{ Alíquotas } \\
\hline & \multirow{2}{*}{ Ad Valorem } & \multicolumn{2}{|c|}{ Específica } \\
\hline & & Maço & Box \\
\hline $1 / 12 / 2011$ a $30 / 4 / 2012$ & $0 \%$ & $\mathrm{R} \$ 0,80$ & $\mathrm{R} \$ 1,15$ \\
\hline $1 / 5 / 2012$ a $31 / 12 / 2012$ & $40,0 \%$ & $\mathrm{R} \$ 0,90$ & $\mathrm{R} \$ 1,20$ \\
\hline $1 / 1 / 2013$ a $31 / 12 / 2013$ & $47,0 \%$ & $\mathrm{R} \$ 1,05$ & $\mathrm{R} \$ 1,25$ \\
\hline $1 / 1 / 2014$ a $31 / 12 / 2014$ & $54,0 \%$ & $\mathrm{R} \$ 1,20$ & $\mathrm{R} \$ 1,30$ \\
\hline $1 / 1 / 2015$ a $30 / 4 / 2016$ & $60,0 \%$ & $\mathrm{R} \$ 1,30$ & $\mathrm{R} \$ 1,30$ \\
\hline $1 / 5 / 2016$ a $30 / 11 / 2016$ & $63,3 \%$ & $\mathrm{R} \$ 1,40$ & $\mathrm{R} \$ 1,40$ \\
\hline A partir de $10 / 12 / 2016$ & $66,7 \%$ & $\mathrm{R} \$ 1,50$ & $\mathrm{R} \$ 1,50$ \\
\hline
\end{tabular}

Fonte: (RFB, 2017). 
Para a análise do mercado consumidor de cigarros, em razão das alíquotas do IPI, adota-se a metodologia da Organização Mundial de Saúde, cuja fórmula é: Produção de cigarros - Exportação de cigarros + Importação de cigarros (INCA, 2017). Desse modo, serão utilizados os dados de "produção", "exportação" e "importação" de fumo, disponíveis no Ipeadata, com periodicidade mensal, e unidade de medida quantum, motivo pelo qual se aplica a alíquota ad valorem, conforme o Gráfico 3, que demonstra a variação dos percentuais de IPI incidentes do período de 2011 a 2016.

Gráfico 3 - Percentual de IPI incidente sobre o fumo no período de 2012 a 2016

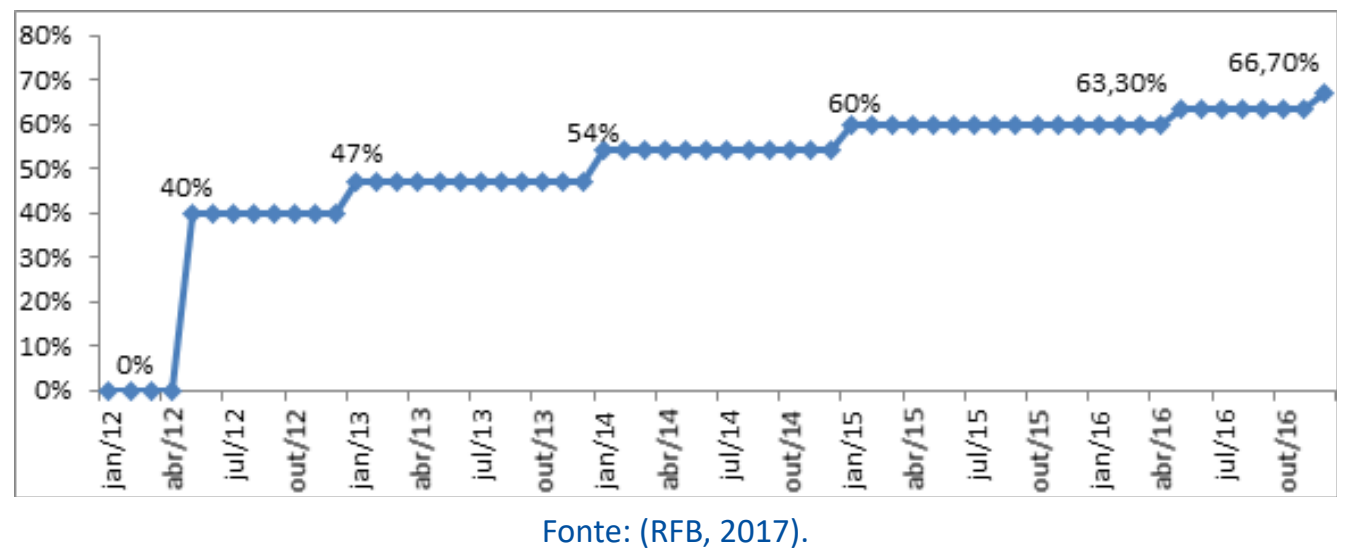

Como forma de análise, adota-se idêntico critério aplicado ao mercado consumidor de veículos, qual seja, divide-se o período de 2012 a 2016 em sete grupos, consoante a variação da alíquota do IPI (Tabela 4), para, posteriormente, se estabelecer o comparativo de consumo entre os períodos, que será obtido por meio da média aritmética do consumo de cada grupo (Gráfico 4).

Tabela 4 - Percentual de IPI incidente sobre o fumo classificados por Grupos no período de 2012 a 2016

\begin{tabular}{|l|l|c|}
\hline Grupos & Período & Alíquota IPI \\
\hline GRUPO A & janeiro a abril de 2012 & $0 \%$ \\
\hline GRUPO B & maio a dezembro de 2012 & $40 \%$ \\
\hline GRUPO C & janeiro a dezembro de 2013 & $47 \%$ \\
\hline GRUPO D & janeiro a dezembro de 2014 & $54 \%$ \\
\hline GRUPO E & janeiro de 2015 a abril de 2016 & $60 \%$ \\
\hline GRUPO F & maio de 2016 a novembro de 2016 & $63,3 \%$ \\
\hline GRUPO G & dezembro de 2016 & $66,7 \%$ \\
\hline
\end{tabular}

Fonte: (RFB, 2017).

Gráfico 4 - Consumo de tabaco em razão das diferentes alíquotas de IPI aplicadas no período de 2012 a 2016

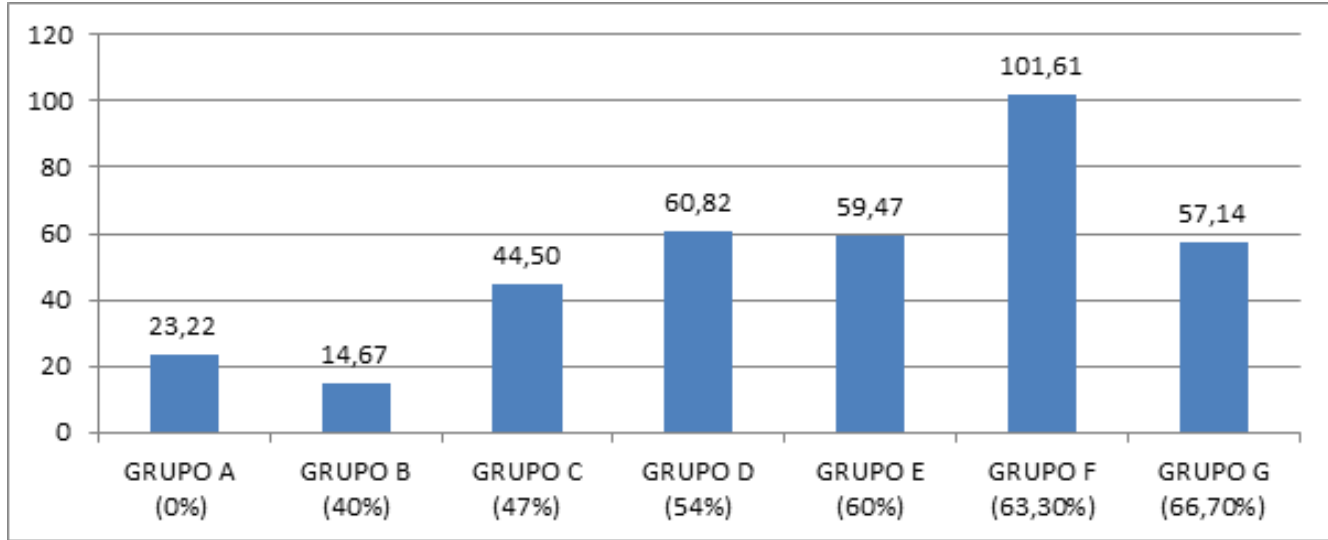

Fonte: IPEADATA (2017). 
Da análise dos dados supradispostos, depreende-se que o mercado consumidor de fumo se distingue do mercado consumidor de veículos em razão da essencialidade dos produtos. Enquanto na análise do primeiro o consumo aumentou em virtude da redução das alíquotas do IPI, que desonerou o preço do produto final, no caso do fumo o aumento das alíquotas não ensejou uma reação do mercado, no sentido de privar o consumo. Ao contrário, a elevação gradativa da alíquota no decorrer do período adotado não obstou a escalada ascendente do consumo de cigarros, sobretudo no que concerne ao Grupo $\mathrm{F}$, cuja alíquota majorada de $63,30 \%$ não inibiu o consumo, que chegou a superar em $41,47 \%$ o consumo alcançado no período anterior, de janeiro de 2015 a abril de 2016 (Grupo E).

O baixo consumo notado no Grupo $G$ não pode se constituir em parâmetro para se estabelecer um comparativo entre a alíquota majorada, de $66,70 \%$, em face do consumo reduzido, porquanto o referido grupo abrangeu somente o mês de dezembro de 2016. Embora nos dois casos (veículos e tabaco) a alteração das alíquotas do IPI seja resultado de medidas extrafiscais, os objetivos do governo na adoção dessas medidas são distintos. Na situação dos veículos, a redução da alíquota, fundamentada no princípio da seletividade, é explicada pela essencialidade do veículo, que estimulou uma reação direta e imediata do mercado consumidor em razão da alteração do preço final do bem. O mercado automotivo constitui-se, portanto, um importante mecanismo de intervenção do Estado na economia, na medida em que o aumento ou a diminuição da procura pode determinar os níveis de renda e emprego na economia.

Também, sob o prisma do princípio da seletividade, as medidas extrafiscais do governo no mercado do tabaco não têm o condão de estimular ou desestimular o segmento produtivo. Por ser o tabaco um produto não essencial e nocivo, que representa um problema de saúde pública, o governo aplica uma alta carga tributária para desestimular o consumo e, por consequência, minorar os efeitos nocivos do tabagismo à população. Para a série adotada - 2011 a 2016 -, porém, a demanda do produto apresentou-se inelástica, ou seja, a elevação da carga tributária não provocou uma reação do mercado consumidor no sentido de desestimular o consumo.

Neste ponto, é importante realçar que o desestímulo ao tabagismo não se encontra atrelado à alta tributação em desfavor do produto. Em realidade, encontra-se diretamente relacionado com as políticas públicas de conscientização dos efeitos negativos do fumo à saúde, dentre os quais se destaca a Lei no 9.294/96, a qual restringiu a propaganda de produtos fumígeros. Logo, a omissão da publicidade direcionada ao mercado do fumo pode produzir maiores efeitos do que uma política tributária austera.

Assim, a intervenção do Estado na indústria do tabaco não gera efeitos imediatos no consumo; ao contrário, somente inviabiliza o investimento por parte do produtor, na medida em que diminui a produtividade. Ademais, não obstante o fato de o mesmo se constituir em uma questão de saúde pública, a interferência estatal se vê impedida, nesta esfera de produção, em face de a atividade ser um instrumento de alavancagem da economia, no que diz respeito à geração de emprego e renda. Conclui-se, desse modo, que, além da inviabilidade do direcionamento de políticas econômicas à indústria do tabaco, a elevação da carga tributária, no período de 2012 a 2016, não produziu efeitos diretos e imediatos em relação ao consumo do bem, pois sua demanda é inelástica.

\section{CONSIDERAÇÕES FINAIS}

O Estado intervencionista foi instituído, em contraposição ao Estado liberal, para enfrentar as falhas de mercado, que assim podem ser relacionadas: indivisibilidades, externalidades, custos de produção decrescentes e mercados imperfeitos, e riscos e incertezas na oferta dos bens. Nesse sentido, o Estado assume as funções: alocativa, relacionada ao fornecimento de bens e serviços não oferecidos adequadamente pelo sistema de mercado; redistributiva, para promover a distribuição de renda; e estabilizadora, para manter certo nível de utilização dos recursos e estabilizar o valor da moeda.

Das formas de intervenção do Estado na economia, abordou-se, neste trabalho, a extrafiscalidade do IPI, na perspectiva do princípio da seletividade, o qual adota a essencialidade do produto como parâmetro para se estabelecer as alíquotas do IPI. Assim, escolheu-se os mercados consumidores de veículos e tabaco, os quais, submetidos às variações de percentuais de IPI, obtiveram diferentes resultados. 
Para o mercado de veículos, a inversão na proporcionalidade dos resultados, ou seja, quanto maior a alíquota de IPI menor o número de emplacamentos e vice-versa, evidencia, além da elasticidade do produto em razão das modificações de seu preço, a possibilidade de o Estado exercer suas funções redistributiva e estabilizadora. Na primeira, a redução no preço, viabiliza o acesso ao produto às populações de baixa renda; e a segunda, produz efeitos na esfera macroeconômica, por meio do fomento do setor produtivo de veículos.

Os resultados da política extrafiscal para o mercado de tabaco foram totalmente inversos ao setor de veículos. Isso porque as alterações na alíquota do IPI não produziram os resultados almejados no mercado consumidor, qual seja, a redução no percentual do IPI não foi apta a reduzir o consumo do tabaco. Este comportamento evidencia a inelasticidade do produto, ou seja, a elevação no preço de cigarros não inibe seu consumo. Tal fenômeno pode assim ser explicado: a dependência produzida pelo uso do cigarro torna o consumidor insensível à elevação de seu preço. Para este caso, mais eficientes são as políticas públicas de conscientização dos efeitos danosos do consumo do tabaco.

Ante o exposto, depreende-se que a política extrafiscal consubstancia o Estado Interventor na aplicação de seus objetivos, sobretudo econômicos, como no caso do setor de veículos, cuja alteração das alíquotas promoveu o desenvolvimento do setor com respectivos efeitos na política macroeconômica do Estado. A aplicação de medidas extrafiscais, todavia, deve estar fundamentada no princípio da seletividade, cujo parâmetro é a essencialidade do produto. Ou seja, produtos considerados não essenciais não devem ser objeto dessa política econômica, a exemplo do tabaco, pois, por serem inelásticos, não apresentarão resultados consoante as variações de alíquota de IPI.

\section{REFERÊNCIAS}

BRASIL. Lei no 5.172, de 25 de outubro de 1966. Dispõe sobre o Sistema Tributário Nacional e institui normas gerais de direito tributário aplicáveis à União, Estados e municípios. Denominado Código Tributário Nacional pelo art. 70 do Ato Complementar no 36, de 13.3.1967. Disponível em: http://www.planalto.gov.br/ccivil_03/Leis/L5172.htm. Acesso em: 15 jun. 2017.

BRASIL. Constituição da República Federativa do Brasil. Brasília, DF: Senado Federal: Centro Gráfico, 1988. 292p.

CHIESA, C. IPI - Compostura das regras-matrizes e a essencialidade dos produtos como fator determinante na fixação da carga tributária. 2013. 244 f. Dissertação (Mestrado em Direito) - Pontifícia Universidade Católica de São Paulo, São Paulo, 2013.

COÊLHO, S. C. N. Curso de Direito Tributário Brasileiro: revista e atualizada de acordo com o Código Civil de 2002. 9. ed. Rio de Janeiro: Forense, 2008.

FALCÃO, M. A. A teoria econômica clássica do tributo. Revista de Direito Empresarial, Belo Horizonte, v. 9, n. 3, p. 123-144, set./ dez. 2012.

FENABRAVE. Quantitativos de veículos emplacados em 2017. Disponível em: www3.fenabrave.org.br:8082/plus/modulos/listas/index.php?tac=indices-e-numeros\&idtipo=1\&id=725\&layout=indices-e-numeros. Acesso em: 19 maio 2018.

FERRARI, N. R. O Estado intervencionista e seus limites. Interesse Público, Belo Horizonte, 18(96), p. 15-26. 2016.

FERRAZ, L.; GODOI, M. S.; SPAGNOL, W. B. Curso de Direito Financeiro e Tributário. 2. ed. Belo Horizonte: Fórum, 2017.

FRANÇA, V. Considerações sobre a intervenção do Estado na Economia na ordem constitucional brasileira. Revista de Direito Público da Economia, Belo Horizonte, n. 55, p. 81-96, 2009.

INCA. Instituto Nacional do Câncer. A prevalência do tabagismo. 2017. Disponível em: http://www2.inca.gov.br/wps/wcm/ connect/observatorio_controle_tabaco/site/home/dados. Acesso em: 11 jul. 2017.

IPEADATA. Instituto de Pesquisa Econômica Aplicada. 2017. Disponível em: http://www.ipeadata.gov.br. Acesso em: 15 jul. 2017.

KEYNES, J. M. A teoria geral do emprego, dos juros e da moeda. São Paulo: Atlas, 1982.

LUZ, J. S. et al. Procedimentos utilizados na aquisição de veículos, isentos de IPI, que têm como finalidade o transporte autônomo de passageiros. In: SEMINÁRIO DE INICIAÇÃO CIENTÍFICA DO CURSO DE CIÊNCIAS CONTÁBEIS, 8, 2014, Caxias do Sul. Anais [...]. Caxias do Sul: Centro Universitário da Serra Gaúcha, 2014. 12p. Disponível em: http://ojs.fsg.br/index.php/anaiscontabeis/article/view/1180/886. Acesso em: 1o ago. 2017.

MENDES, Judas Tadeu Grassi. Economia: fundamentos e aplicações. 2. ed. São Paulo: ABDF, 2009.

MOREIRA NETO, D. F. O novo papel do Estado na Economia. Revista de Direito Público da Economia, Belo Horizonte, v. 3, n. 11, 2005. Disponível em: http://www.bidforum.com.br. Acesso em: 20 jun. 2017.

SILVEIRA NETO, O. S. A intervenção do Estado no domínio econômico via extrafiscalidade do direito do crédito público brasileiro. Revista de Direito Público da Economia, Belo Horizonte, v. 12, n. 46, 2017. Disponível em: http://www.bidforum.com.br. Acesso em: 15 jun. 2017. 
PAULSEN, L.; MELO, J. E. S. de. Impostos: federais, estaduais e municipais. 8. ed. Porto Alegre: Livraria do Advogado, 2013.

RFB. Receita Federal do Brasil. Imposto sobre produtos industrializados. 2017. Disponível em: http://idg.receita.fazenda.gov.br/ acesso-rapido/tributos/ipi. Acesso em: 1ㅇa. 2017.

RIBEIRO, R. L. Tributos: teoria geral e espécies. Niterói: Impetus, 2013.

RIANI, F. Economia do setor público: uma abordagem introdutória. 6. ed. Rio de Janeiro: LTC, 2016.

SALOMÃO, F. M. Redução do imposto sobre produtos industrializados: uma análise econômico-tributária dos reais efeitos das medidas de incentivo ao mercado automotivo. 2014. Rio de Janeiro, 50f. Monografia (Conclusão do curso de Direito) - Fundação Getúlio Vargas, Rio de Janeiro, 2014.

SAMUELSON, P. A.; NORDHAUS, William D. Economia. 17. ed. Rio de Janeiro: Mc Graw Hill, 2004.

TORRES, R. L. Tratado de Direito Constitucional Financeiro e Tributário: os Tributos na Constituição. 5. ed. Rio de Janeiro: Renovar, 2007.

VALLE, M. D. T. O princípio da seletividade do IPI. Revista do Instituto do Direito Brasileiro, Lisboa, v. 2, n. 9, 2013. Disponível em: http://www.cidp.pt/publicacoes/revistas/ridb. Acesso em: 10 jul. 2017.

VASCONCELLOS, M. A. S. Economia: micro e macro. 6. ed. São Paulo: Atlas, 2015.

VASQUES, S. Origem e finalidades dos impostos especiais de consumo. Revista Fórum de Direito Tributário, Belo Horizonte, v. 3, n. 17, 2005. Disponível em: http://www.bidforum.com.br/bidBiblioteca_periodico. Acesso em: 20 jul. 2017.

WESSELS, W. J. Economia. 3. ed. São Paulo: Saraiva, 2010.

YAMASHITA, D. Direito tributário: uma visão sistemática. São Paulo: Atlas, 2014. 